\title{
The psychophysics of imagery
}

\author{
JOHN C. BAIRD and KATHLEEN A. HARDER \\ Dartmouth College, Hanover, New Hampshire
}

\begin{abstract}
A series of experiments considers the extent to which the interrelations among subjective magnitudes aroused by images corresponds to those for subjective magnitudes aroused by physical stimuli. In Experiment 1, 68 undergraduates typed phrases in response to graded categories regarding the imagined magnitude of lights, sounds, and smells. In Experiment 2, 5 undergraduates and, in Experiment 3, 3 graduate students then magnitude estimated the image intensity aroused by each of these stimulus phrases. In Experiments 4 and 5, the same subjects performed cross-modality matches between phrases arousing images for different attributes (light, sound, and smell). Statistical analysis indicates that estimates based on images display many of the same patterns as those based on physical stimuli. The major exception involves sequence effects, present for actual stimuli but not for images.
\end{abstract}

An outstanding issue in cognitive psychology centers on the degree to which the subjective magnitude aroused by an image corresponds to that aroused by the physical stimulus itself (Finke, 1985; Kosslyn, 1987; Shepard \& Cooper, 1982). Empirical evidence supports the view that many of the brain structures underlying perceptual, primarily visual, processes are the same as those responsible for imagery (Farah, 1985, 1989, 1995; Kosslyn, Thompson, Kim, \& Alpert, 1995; Roland \& Gulyás, 1994). And even if the brain structures for imagery and perception are not identical down to the last neuron, these studies implicate at least a functional equivalence between the two: The cognitive/judgment processes called upon in perception experiments resemble those called upon in imagery experiments (Finke, 1985, 1989; Finke \& Shepard, 1986; Hubbard \& Stoekig, 1992).

Despite mounting evidence to the contrary, other accounts of the facts imply that a theory of imagery should have little or nothing to do with a theory of perception, from the standpoint of either psychology or neurophysiology. One such alternative claims that subjects in imagery experiments guess what the experimenter expects of them, and, consequently, they give the "expected" judgments in response to instructions to imagine a stimulus (Intons-Peterson, 1983, 1984; Intons-Peterson \& McDaniel, 1991; Intons-Peterson \& White, 1981; Mitchell $\&$ Richman, 1980). Another possibility is that experimenter bias (Rosenthal, 1976) accounts for imagery results or that the subject's tacit knowledge of the relation between images and percepts is somehow involved (Pylyshyn,

K. A. Harder is currently at the Human Factors Research Laboratory, University of Minnesota. The authors thank Gemma Ross for assistance in conducting Experiments 2 and 4 . David M. Green kindly provided us with data on the magnitude estimation of sounds. The authors also thank Danny Algom, Lawrence Ward, Lawrence Marks, Scott Parker, and Bruce Schneider for constructive comments on an earlier version of the paper. Correspondence should be addressed to J. C. Baird, Department of Psychological and Brain Sciences, Dartmouth College, Hanover, NH 03755 (e-mail: john. c.baird@dartmouth.edu).
1984). The main thrust of these arguments has been largely neutralized by Kosslyn (1994) and others (e.g., Farah, 1995; Finke, 1985). There seems to be no question that experimenters can unwittingly influence imagery judgments (Intons-Peterson, 1983), just as they can influence perceptual judgments (Poulton, 1989), but this bias alone cannot explain the vast majority of research findings in either area.

What is still lacking in discussions of the functional equivalence between imagery and perception is a tight coupling between results from the two domains beyond the level of first-order statistics. Imagery studies conducted by cognitive researchers seldom report any statistics besides the arithmetic mean, and little or no attempt is made to incorporate the results into current physiological or psychological models of perception and psychophysics. On the other hand, psychophysicists often treat imagery as legitimate subject matter for theory development (Algom, 1992; Baird \& Hubbard, 1992; Hubbard, 1994).

A defining feature of current psychophysical theory is that it considers a wide array of statistical measures and, in this way, attempts to partial out the relative contributions of stimulus and response context in determining judgments (Baird, 1997; Link, 1992; Marks, 1993; Norwich, 1993; Poulton, 1989). Some imagery experiments are guided by this framework (Algom, 1992; Hubbard, 1993; Hubbard \& Baird, 1988, 1993; Hubbard, Kall, \& Baird, 1989), but, on the whole, data analyses from imagery studies are limited in scope. In the present experimental series, our purpose was to expand the potential impact of imagery research by conducting a battery of analyses commonly employed in studies of the perception of physical intensities.

Specifically, we had subjects estimate the imagined magnitude of stimulus intensity aroused from reading phrases describing scenes featuring the attributes of light, sound, and smell. We employed procedures that mimic those in psychophysical experiments and collected data on the following measures and functional relationships: (1) number behavior associated with the method of mag- 
nitude estimation, (2) the relation between category and magnitude estimates, (3) cross-modality matches, (4) the coefficient of variation (CV) as a function of stimulus intensity, (5) the skewness of response distributions, (6) sequential dependencies among successive responses, and (7) errors in the rank ordering of successive stimuli.

At the outset, we held no firm hypotheses about how the experiments might turn out; that is to say, we were impartial as to whether or not estimates based on images would reveal a pattern similar to that seen for physical stimuli. For this and other reasons noted below, we doubt if experimenter expectancy or demand characteristics were factors of any importance. Moreover, the reasoning behind our statistical measures is almost certainly opaque to a naive subject. Our intent was to investigate the imagery issue in a way that would foster the development of quantitative theories linking perception and imagery.

\section{EXPERIMENT 1}

Classical psychophysics rests most heavily on one central premise: When the same stimulus is presented for judgment on many occasions, it results in different responses. These responses may differ because the sensory system does not always process the stimulus in the same manner, because the stimulus exhibits fluctuations due to physical/neural processes, or because the subject is variable in deciding on the response to assign. This is the foundation for many empirical laws as well as the basis for signal detection theory. We are talking here about the impact of just one stimulus. The experimental data reflecting this variability are summarized by the statistical moments of the response distribution obtained for each stimulus presented on multiple occasions to the same person or to different individuals. Over the past 150 years, functional relations have been documented between the mean, the standard deviation, and the skewness of the response distributions, as well as the relations between these statistics and physical measures of the stimulus itself.

The purpose of Experiment 1 was to generate distributions of images, as expressed by phrases, that corresponded to a set of seven descriptive categories (conveying degrees of intensity) for each of three attributes (light, sound, and smell). This phrase pool was the basis for the stimulus and comparison materials in all the subsequent experiments. The results were not subjected to statistical analysis (though we do give examples of the responses). ${ }^{1}$

\section{Method}

Subjects. The subjects were 70 undergraduates ( 35 men and 35 women) enrolled in an introductory psychology course at Dartmouth College. Each received nominal course credit for participation.

Procedure. The subjects received an e-mail message with an enclosed survey, which they completed on a computer of their choice. They returned the completed survey to the experimenter via e-mail.
The survey instructions read in part:

You will be presented with a number of words which describe an object of varying levels of intensity that someone may have experienced. Your task is to type the very first image that comes to mind upon reading the words. For example, if the object were described as "very sweet," you might respond by typing: "A mouthful of chocolate fudge cake." In answering, feel free to use only a few words or up to a sentence.

Seven descriptor categories were given for each of three attributes (light, sound, smell). These were presented in a different random order for each subject. For each category, the subject typed in a phrase to characterize the image aroused. The descriptors for the three attributes were as follows. Light: "a very very bright light," "a very bright light," "an average light," "a weak light," "a very weak light," "a very very weak light." Sound: "a very very loud sound," "a very loud sound," "a loud sound," "an average sound," "a soft sound," "a very soft sound," "a very very soft sound." Smell: "a very very strong smell," "a very strong smell," "a strong smell," "an average smell," "a faint smell," "a very faint smell," "a very very faint smell."

\section{Results}

Data from 2 subjects were discarded because they generated phrases with potentially offensive meaning. This left a total of 68 subjects, each of whom produced 21 phrases ( 7 for each of three attributes). This created a distribution of 68 points (phrases) for each attributecategory pair and a total stimulus pool of $68 \times 7 \times 3=$ 1,428 phrases.

Examples of representative phrases for each of the three attributes are given in the Appendix.

\section{EXPERIMENT 2}

The purpose of Experiment 2 was to obtain magnitude estimates of the intensity of the image elicited by each of the phrases generated in Experiment 1. These estimates were then compared with the descriptor categories (converted to integers 1-7) used as stimuli in Experiment 1. This conversion is based on the untested assumption that the scale distances between adjacent descriptor categories are equal to each other. In the absence of relevant data for the present application, equal spacing between categories is the simplest (and most practical) assumption. It should be noted, however, that in other applications (regarding pain descriptors), this assumption is not always valid (Gracely, McGrath, \& Dubner, 1978; Heft \& Parker, 1984). In addition, psychophysical analyses were performed to determine the correspondence between estimates based on induced images and estimates based on actual, physical stimuli (reported in previous studies noted in the introduction).

\section{Method}

Subjects. The subjects were 5 undergraduates $(3$ women and 2 men) enrolled in an introductory psychology course at Dartmouth College. Each received nominal course credit for participation.

Procedure. The experiment was conducted on a Macintosh platform. The stimulus phrases were those generated by the subjects in Experiment 1. No further pruning of the phrase pool was under- 
taken. This meant that some of the phrases were identical or nearly so. By using the entire pool, we tried to secure a representative sample of the population of imagined scenes for each category (including differences in relative probability of occurrence). That is, we argue that a phrase with many duplicates should receive a greater number of presentations than a phrase with no duplicates because the former apparently has a higher probability of occurrence in the collective image pool than does the latter. Many of the phrases were short (see the Appendix). Out of the $\mathbf{4 7 6}$ available for each attribute, there were 89 exact phrase duplicates for light, 73 for sound, and 59 for smell.

For each subject, the entire set of 1,428 phrases was randomized and divided into three equal groups of 476 each. This meant that attributes and their seven levels of intensity were intermixed over trials within a session. The subjects then were tested individually in three sessions separated by 1 day or 2 days ( 476 phrases per session).

The instructions read in part:

You will be presented with a series of scenarios involving sounds, lights, and smells. Imagine that you are experiencing the actual physical intensity associated with each scenario. Type any number from 1 to 100 (smaller numbers represent a less intense feeling and larger numbers represent a more intense feeling) that you think most accurately reflects the number you would give if you were in the actual physical situation.

We restricted the range of numbers from 1 to 100 because we wanted to reduce the variance associated with judgments across a small group of subjects. An open-ended response scale was employed in Experiment 3, with essentially the same outcome. Gibson and Tomko (1972) found that a scale of $1-100$ produced data that were statistically indistinguishable from data obtained with an open-ended scale.

Before starting the first session, three practice trials were run to familiarize the subjects with the procedure. None of these trials' phrases was included in the experiment proper. Phrases were presented in a different random order for each subject. A phrase appeared in the center of the screen, and the subject typed a number to represent estimated intensity. Typing "return" cleared the screen, and the next phrase appeared. Each session lasted approximately $25 \mathrm{~min}$.

\section{Results and Discussion}

Number behavior. Our initial analysis considers number preferences. The database for each subject was parsed into categories reflecting the frequency with which each number was given, as the subject imagined scenes involving the three attributes. All the numbers typed as responses were rank ordered and classified into four bins representing $25 \%, 50 \%, 75 \%$, and $100 \%$ of the total number of responses. Table 1 presents the number of different response values below each of these cutoffs. The means across all 5 subjects were similar to those obtained for physical sounds and open-ended response scales (21 stimuli; Green, Luce, \& Duncan, 1977) and odors (8 stimuli; Baird, Berglund, \& Olsson, 1996). The comparable values from the latter studies (from Baird, 1997, Table 15.1) are shown below the means (Table 1) obtained for sound and smell in the present experiment. For both imagined and physical stimuli, the subjects produce a small set of whole numbers to represent perceived magnitudes.

The rightmost column of Table 1 gives the entropy (uncertainty) of each response set ( $R$ ), as computed in the usual fashion (Baird \& Noma, 1978, chap. 12):

$$
\mathrm{U}(\mathrm{R})=-\sum_{j=1}^{M} p\left(r_{j}\right) \log _{2} p(r) .
$$

The relative frequency of each response type $\left(r_{j}\right)$ was equated with a probability and substituted into Equation 1 to determine average response uncertainty for the total set, separately for each attribute. As seen in Table 1, the average response uncertainty associated with images of sound and smell compare favorably with values derived from loudness (4.6 bits) and odor ( 4.5 bits) estimates of physical stimuli (Baird, 1986, 1997, Table 15.1).

Category descriptors and magnitude estimates. It has been known at least since 1957 that magnitude estimates are a positively accelerated function of category estimates obtained for the same physical stimuli (S. S. Stevens \& Galanter, 1957). This finding has since been verified many times (for references, see Baird, 1997, p. 131).

The qualitative descriptors used in Experiment 2 were converted into the integers $1-7$. The arithmetic mean of the corresponding magnitude estimates were then plotted as a function of the associated category, separately for each attribute, but across all 5 subjects. The results

Table 1

\begin{tabular}{|c|c|c|c|c|c|}
\hline \multicolumn{6}{|c|}{$\begin{array}{l}\text { Number of Response Options and Response Uncertainty for } \\
\text { Magnitude Estimates of Phrases Arousing Images of } \\
\text { Light, Sound, and Smell in Experiment } 2\end{array}$} \\
\hline \multirow[b]{2}{*}{ Subject } & \multicolumn{4}{|c|}{ Percentage } & \multirow[b]{2}{*}{$U(R)$} \\
\hline & 25 & 50 & 75 & 100 & \\
\hline \multicolumn{6}{|c|}{ Light } \\
\hline 1 & 3 & 10 & 25 & 73 & 5.4 \\
\hline 2 & 2 & 5 & 11 & 51 & 4.6 \\
\hline 3 & 1 & 4 & 7 & 18 & 3.6 \\
\hline 4 & 1 & 3 & 6 & 27 & 3.7 \\
\hline 5 & 1 & 2 & 7 & 51 & 4.0 \\
\hline Mean & 1.6 & 4.8 & 11.2 & 44.0 & 4.3 \\
\hline \multicolumn{6}{|c|}{ Sound } \\
\hline 1 & 3 & 9 & 21 & 65 & 5.2 \\
\hline 2 & 2 & 7 & 15 & 56 & 4.9 \\
\hline 3 & 1 & 4 & 8 & 21 & 3.9 \\
\hline 4 & 1 & 3 & 6 & 31 & 3.8 \\
\hline 5 & $i$ & 3 & 8 & 52 & 4.2 \\
\hline Mean & 1.6 & 5.2 & 11.6 & 45.0 & 4.4 \\
\hline $\begin{array}{c}\text { Green et al. } \\
\text { mean* }\end{array}$ & 2.6 & 7.4 & 15.0 & 60.0 & 4.6 \\
\hline \multicolumn{6}{|c|}{ Smell } \\
\hline 1 & 3 & 9 & 24 & 70 & 5.4 \\
\hline 2 & 2 & 5 & 11 & 48 & 4.6 \\
\hline 3 & 1 & 2 & 6 & 17 & 3.4 \\
\hline 4 & 1 & 2 & 6 & 31 & 3.6 \\
\hline 5 & 1 & 2 & 75 & 45 & 3.8 \\
\hline Mean & 1.6 & 4.0 & 24.4 & 42.2 & 4.2 \\
\hline $\begin{array}{c}\text { Baird et al. } \\
\text { mean } \dagger\end{array}$ & 2.5 & 6.5 & 13.0 & 42.0 & 4.5 \\
\hline
\end{tabular}

Note-U(R) refers to response uncertainty in bits (from Equation 1). *Green et al. (1977), 21 stimuli (from Baird, 1997, p. 266). ${ }^{\dagger}$ Baird et al. (1996), 8 stimuli (from Baird, 1997, p. 266). 

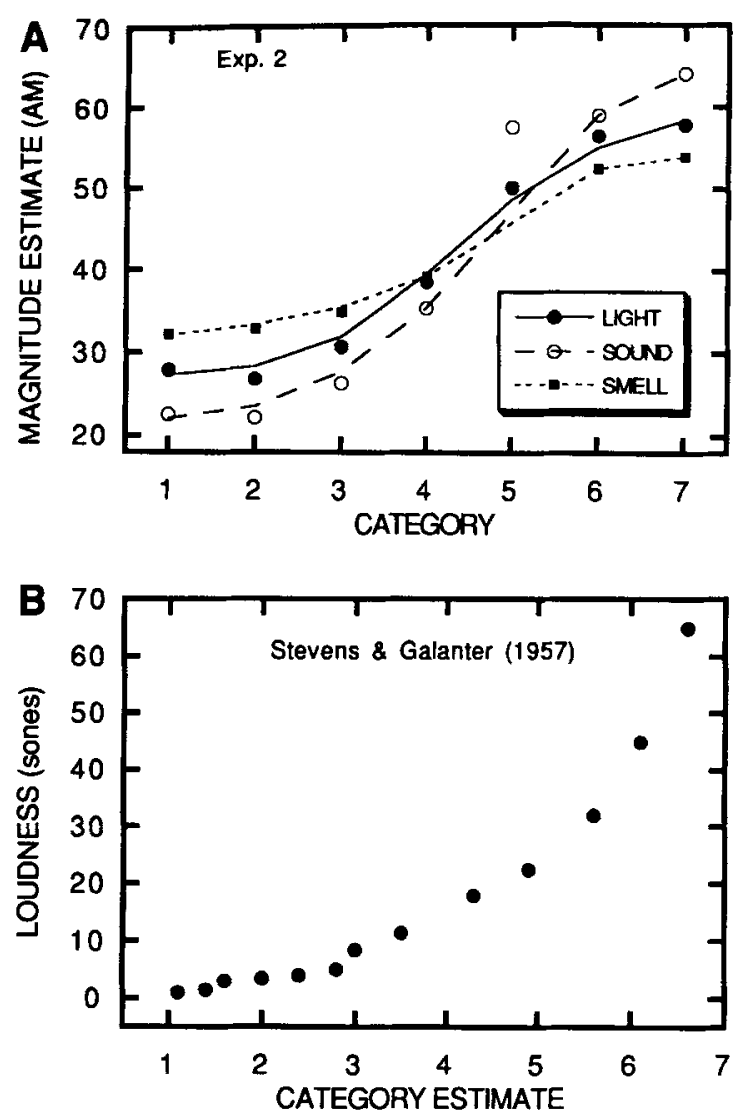

Figure 1. Magnitude estimates (arithmetic means for 5 subjects) as a function of phrase category value. (A) Average data from Experiment 2 for images of light, sound, and smell. (B) Data for loudness of physical sounds (S. S. Stevens \& Galanter, 1957).

are shown in Figure 1A, where the lines through the points represent a weighting function used to emphasize the general trends. The familiar positive acceleration is evident for the smallest categories, but a deceleration occurs for the largest categories. This suggests that the subjects did not exhibit clear discrimination among the phrases generated in response to the very lowest and very highest categories. It should be noted that the response range for the magnitude estimates is not as pronounced as is typically seen for physical stimuli. The response range for images of sound is the largest, followed by the ranges for light and smell. It is not clear whether this ordering of the modalities reflects differences in the ability of the subjects in Experiment 1 to generate clear scenarios or, rather, reflects some other interaction between judgment behavior and attribute.

In the original study with physical stimuli (S. S. Stevens \& Galanter, 1957), an exponential function provides a good fit when magnitude estimates are plotted against category estimates. Their data for loudness are shown in Figure 1B, where it can be seen that the curve is positively accelerated throughout the entire scale of category values. The range of magnitude estimates is greater here than in the imagery experiment (Figure 1A); this may be the reason our imagery functions do not correspond to the psychophysical functions at the high end of the scale. This conclusion is supported by the results of an unpublished study (Harder \& Baird, 1995, described in Baird, 1997, p. 132), in which we gave subjects seven verbal categories varying in level from "very very weak" to "very very strong" (lights or sounds) and asked them to assign numbers to characterize the image aroused by each label. The range of magnitude estimates was similar to that reported by S. S. Stevens and Galanter, and the trend was positively accelerated throughout the entire category scale. In this earlier study, the results for images were very close to those for physical stimuli, suggesting that our present data may be affected by the restricted range of application.

Coefficient of variation. The standard deviation of the magnitude estimates for each descriptor category was calculated separately for each subject and divided by the mean to find the CV. These values were then averaged across all 5 subjects and are plotted in Figure 2A as a function of descriptor category. The average $\mathrm{CV}$ declines with increases in the category integer, ranging from approximately 0.8 to 0.4 .
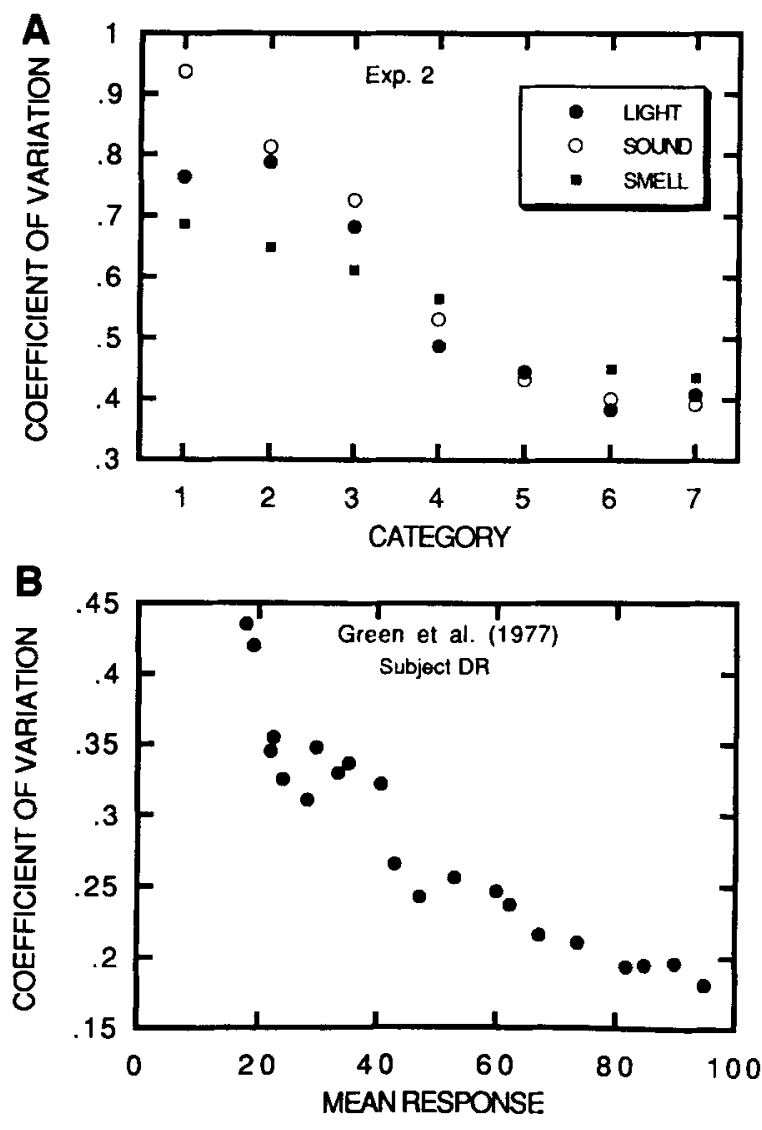

Figure 2. CV (standard deviation/mean) as a function of category value. (A) Average data from Experiment 2 for images of light, sound, and smell. (B) Data for loudness of physical sounds (Green et al., 1977). 
For comparison purposes, in Figure 2B, we show the $\mathrm{CV}$ in loudness judgments for a typical subject from a study by Green et al. (1977). The CVs from this study (sounds) are less than values obtained for images, but, in other studies, the CVs for estimates of physical odorants (Baird et al., 1996) are about the same as reported here for images.

Skewness. The skew of the response distributions was calculated for each subject and then separately averaged for each attribute. The results are displayed in Figure 3A. The distributions are positively skewed for the smaller categories, and skew declines with increases in the presumed intensity of the attribute in the image. At the highest intensities, the skew becomes negative for sound and light. Figure 3B shows comparable data for a typical subject judging sounds (Green et al., 1977). Both the trends and the absolute values of skewness are similar in Figures $3 \mathrm{~A}$ and $3 \mathrm{~B}$.

Sequence effects. A substantial amount of research has been devoted to the issue of sequential dependencies among successive responses in the method of magnitude estimation (Baird, 1997, chap. 13). Two standard analyses are presented here for images: percent of incorrect rank
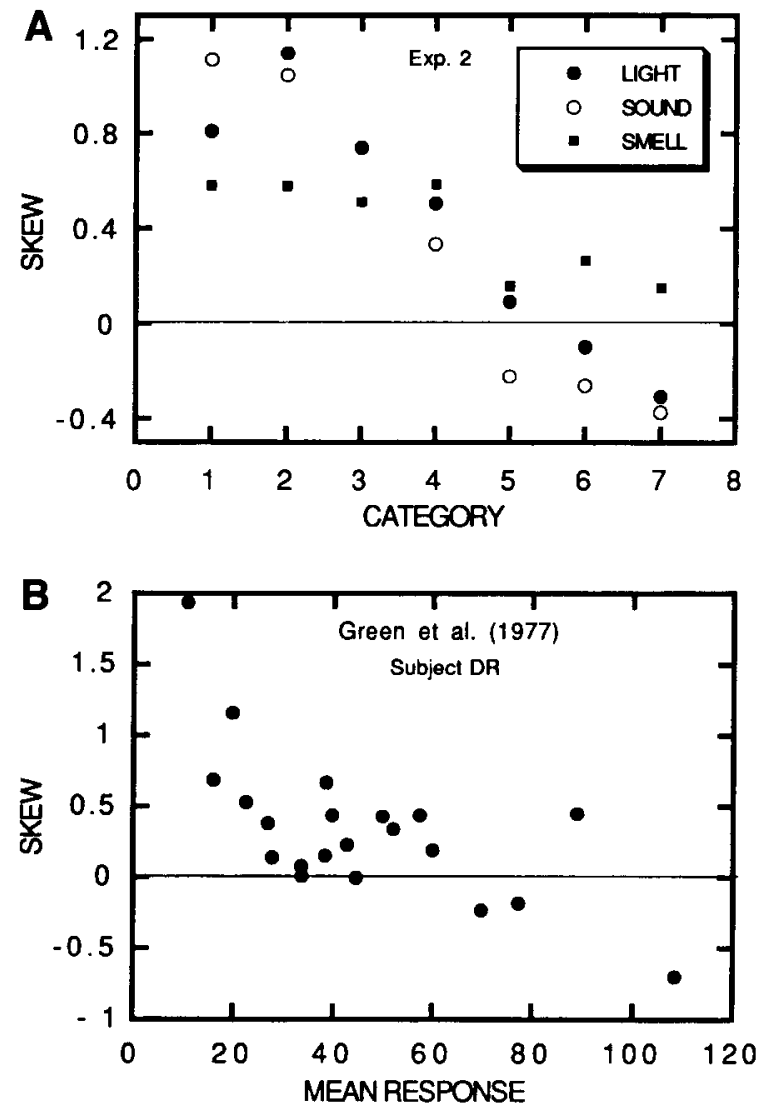

Figure 3. Skew of response distributions as a function of category value. (A) Average data from Experiment 2 for images of light, sound, and smell. (B) Data for loudness of physical sounds (Green et al., 1977).
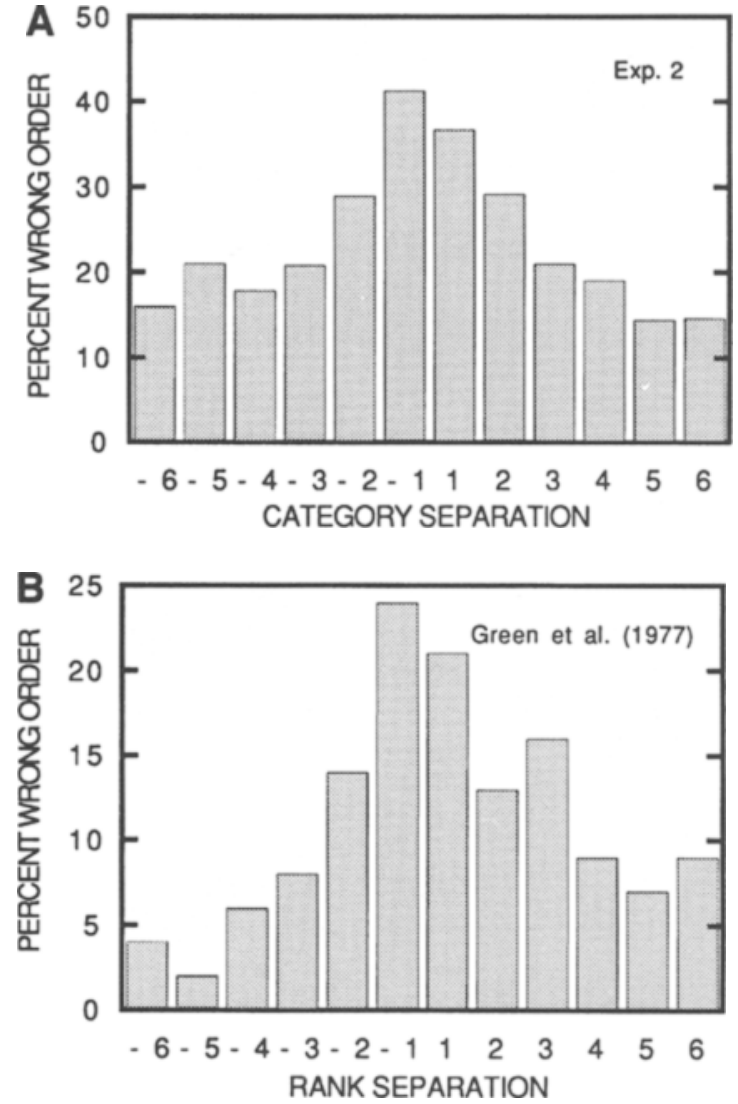

Figure 4. Percent violation of rank order between estimates of successive stimuli as a function of stimulus rank separation. (A) Average data from Experiment 2 for images of light, sound, and smell. (B) Data for loudness of physical sounds (Green et al., 1977).

order over trials, and the correlation among successive response magnitudes.

Figure 4A shows the percent of trials on which the subjects made an "error" in the rank ordering of successive images (phrases elicited by categories $1-7$ ) as a function of the rank-order separation between successive phrases. A violation (error) of rank order occurs when successive responses $(\mathrm{R})$ on Trials $\mathrm{N}$ and $\mathrm{N}-1$ relate to successive categories (C) in one of two ways: If $C_{N}>$ $\mathrm{C}_{\mathrm{N}-1}$, then $\mathrm{R}_{\mathrm{N}}<\mathrm{R}_{\mathrm{N}-1}$; or, if $\mathrm{C}_{\mathrm{N}}<\mathrm{C}_{\mathrm{N}-1}$, then $\mathrm{R}_{\mathrm{N}}>\mathrm{R}_{\mathrm{N}-1}$. Violations were first tabulated for each subject and attribute and then averaged. The highest percentages occur when the successive phrases are close in rank; errors decline as the rank orders of successive phrases separate more and more. This pattern is identical to that found when subjects estimate physical stimuli, an example of which is shown in Figure 4B for loudness estimates (Green et al., 1977; from Baird, 1997). The percent errors for images (Figure 4A) are greater than comparable values for physical stimuli (Figure 4B).

Another measure of sequential dependencies is the correlation between sets of successive responses, determined for each possible pair of stimulus intensities over 
the entire experiment. This measure is plotted as a function of category separation of successive stimuli. The usual result for physical stimuli is a high correlation between successive responses (approximately $r=.8$ ) when two stimuli are similar in intensity. For example, on Trial $\mathrm{N}-1$, if the subject employs a small number (as a response) relative to the full set obtained for that particular stimulus over the course of the entire experiment, then, on the next trial $(\mathrm{N})$, a small number will be given relative to the full set obtained for that stimulus over the course of the experiment. As the rank separation between successive stimuli increases, the correlation declines to zero for the widest separations (Baird, Green, \& Luce, 1980; Green et al., 1977). This trend is known as the triangle pattern (Luce, Baird, Green, \& Smith, 1980).

The results of this analysis for images are shown in Figure $5 \mathrm{~A}$. The correlation hovers around zero for all stimulus separations. No apparent dependencies occur as a function of the intensity of successive images aroused by phrases. This finding differs markedly from the results for physical stimuli, which are shown in Figure 5B for a group of subjects estimating the loudness of sounds (Green et al., 1977, from Baird, 1997, p. 221).

The reason for this difference may be that an image elicited by a phrase contains much more information than a single intensity variable. Consequently, successive images associated with similar category descriptors need not correspond very closely in terms of image similarity. According to one theory, the judgment option model (elaborated upon in Baird, 1997, chap. 9), the size of the correlation over successive trials depends on the perceived similarity of successive stimuli. The greater the similarity, the greater the correlation. Unlike the situation with unidimensional laboratory stimuli, for images based on phrases, intensity is only one of many dimensions along which similarity can be assessed.

In sum, except for the lack of sequential dependencies, estimates of images aroused by phrases appear to have the same general statistical properties as estimates of physical stimuli. In Experiment 3, we examined the robustness of these findings by employing a different experimental design and procedure.

\section{EXPERIMENT 3}
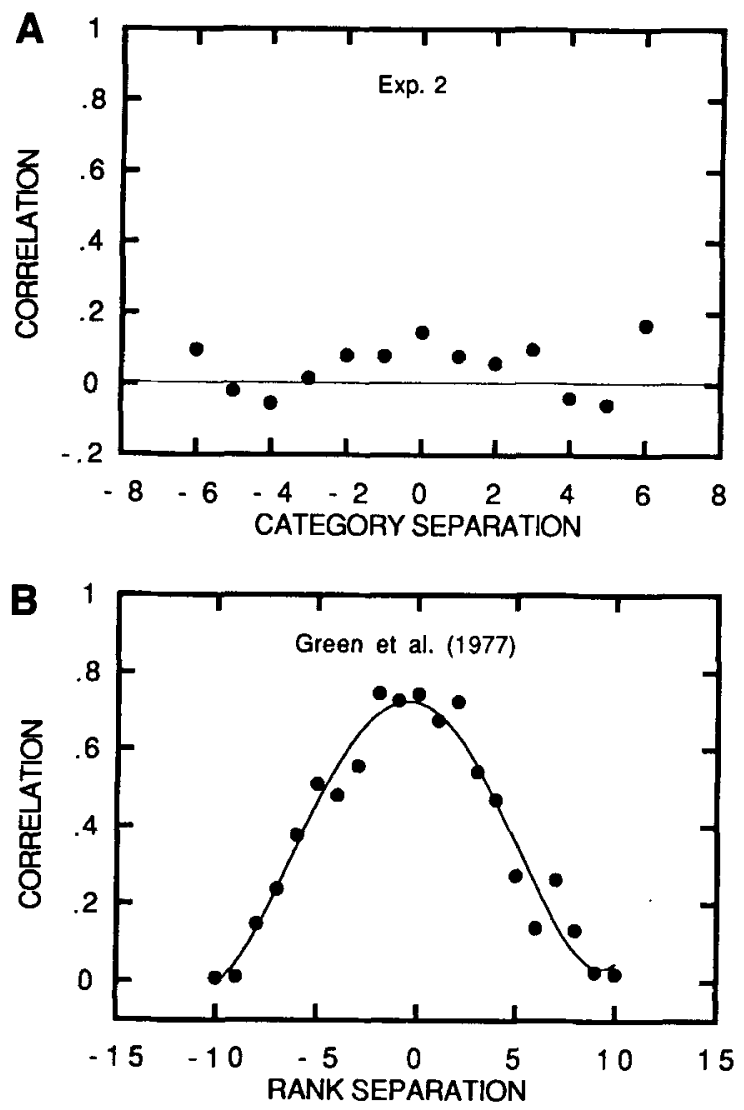

Figure 5. Correlation between successive responses to phrases as a function of stimulus rank separation. (A) Average data from Experiment 2 for images of light, sound, and smell. (B) Data for loudness of physical sounds (Green et al., 1977).
Two methodological considerations suggest other explanations for the lack of sequential dependencies in Experiment 2. First, the attribute phrases were randomly mixed within a session, and this may have diluted the sequence effects. Second, the subjects were all forced to use the same response scale $(1-100)$, and this may be responsible for the weak sequence effect. The purpose of Experiment 3 was to test the generality of the findings of Experiment 2 by (1) employing a new group of subjects, who received the stimulus phrases in blocks containing the same attribute, and (2) by permitting subjects to use their own personal numerical scale in expressing estimates.

\section{Method}

Subjects. The subjects were 3 graduate students (1 man and 2 women) at Dartmouth College. Each received $\$ 50$ compensation.

Procedure. The experiment was conducted on a Macintosh platform, using the same phrases and general approach as in Experiment 2. Two changes were introduced. First, each of the three attributes was presented in a block of 476 phrases per session. The blocks were presented in a partially balanced Latin square design. Second, the subjects were allowed to give any number greater than zero in expressing judgments of image intensity.

The instructions read in part:

You will be presented with a series of scenarios involving lights (sounds, smells). Imagine that you are experiencing the actual physical intensity associated with each scenario. Type any number greater than 0 (smaller numbers represent a less intense feeling and larger numbers represent a more intense feeling) that you think most accurately reflects the number you would give if you were in the actual physical situation.

\section{Results and Discussion}

The data were treated as in Experiment 2 by considering the same dependent measures: number behavior, the 
Table 2

Number of Response Options and Response Uncertainty for Magnitude Estimates of Phrases Arousing Images of Light, Sound, and Smell in Experiment 3

\begin{tabular}{cccccc}
\hline & \multicolumn{5}{c}{ Percentage } \\
\cline { 2 - 6 } Subject & 25 & 50 & 75 & 100 & U(R) \\
\hline & \multicolumn{5}{c}{ Light } \\
2 & 1 & 3 & 6 & 35 & 3.8 \\
3 & 1 & 7 & 13 & 54 & 4.6 \\
Mean & 1.3 & 4.0 & 8.0 & 33.7 & 3.2 \\
& & & Sound & & 3.9 \\
1 & 3 & 7 & 13 & 54 & 4.8 \\
2 & 3 & 7 & 14 & 38 & 4.7 \\
3 & 1 & 3 & 5 & 12 & 3.2 \\
Mean & 2.3 & 5.7 & 10.7 & 34.7 & 4.2 \\
& & & Smell & & \\
1 & 2 & 7 & 14 & 44 & 4.8 \\
2 & 1 & 4 & 9 & 33 & 4.2 \\
3 & 1 & 2 & 5 & 12 & 3.2 \\
Mean & 1.3 & 4.3 & 9.3 & 29.7 & 4.1 \\
\hline
\end{tabular}

Note-U(R) refers to response uncertainty in bits.

relationship between category descriptors and magnitude estimates, CV, skewness, and sequence effects.

Number behavior. The database for each subject was parsed into categories containing the frequency that each number was given for each of the three attributes. The numbers were rank ordered and classified as described for Experiment 2. The entropy (uncertainty) of each response set was then obtained by substituting response probabilities (relative frequency of occurrence) into Equation 1.

Results are presented in Table 2, which has the same format as Table 1. The frequency of number usage and the entropy (uncertainty) values are comparable to those found when subjects are restricted to a response scale from 1 to 100 and receive phrases for all three attributes mixed together in the same session (Experiment 2). One of the subjects (Subject 3 ) in Experiment 3 gave only integers from 1 to 12 , and this depressed the averages to levels somewhat below those in Experiment 2. The use of a limited number of response options is not exceptional in magnitude estimation when subjects choose their own response scales (Baird, 1986, 1997, p. 266).

Category descriptors and magnitude estimation. The category descriptors were converted to the integers $1-7$. Figure 6 shows the geometric means ${ }^{2}$ of magnitude estimates plotted against the corresponding categories. The lines through the data points represent weighted functions to emphasize the overall trends. All three functions show a compression of magnitude estimates at the low end of the category scale, but, unlike the findings in Experiment 2 (Figure 1A), a similar compression does not appear at the high end of the scale. In this respect, the data correspond more closely to what is found with estimates of physical stimuli (Figure 1B). It is possible that the ambiguity regarding the quantitative form of such data would be resolved by inducing a wider response range.

Coefficient of variation. Figure 7 shows the CVs (standard deviation divided by the arithmetic mean) as a function of descriptor category for each of the attributes. These data agree with those from Experiment 2 (Figure $2 \mathrm{~A}$ ), though the $\mathrm{CV}$ in Experiment 3 is somewhat smaller. The results mimic to an even greater extent those for physical stimuli, which are usually estimated in blocks of trials containing the same attribute (Figure 2B; Baird, 1997, p. 166).

Skewness. Figure 8 shows the skewness of the response distributions (averaged across 3 subjects) as a function of the category descriptor. The distributions are positively skewed for the small categories (weak images), whereas the skewness is near zero for the larger categories. Although the overall skewness is greater here than in Experiment 2, the general pattern (decline of skewness value with intensity) is similar (Figure $3 \mathrm{~A}$ ) and

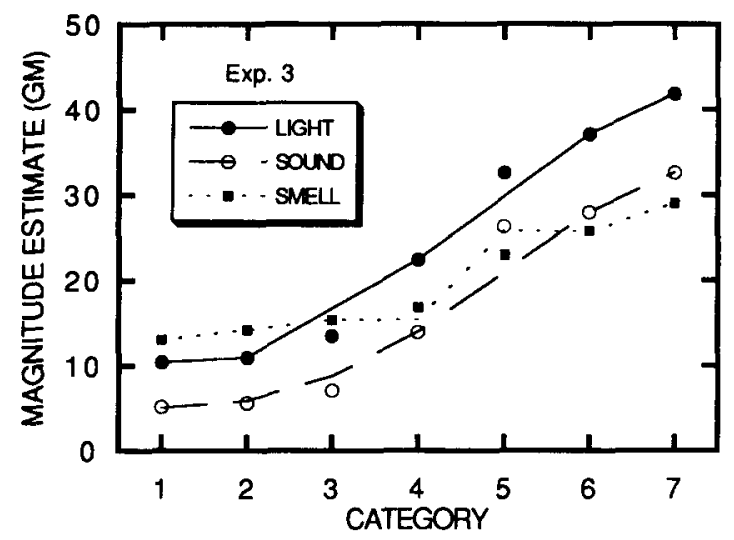

Figure 6. Magnitude estimates (geometric means for 3 subjects) as a function of phrase category value for the attributes indicated. Data based on averages across 3 subjects in Experiment 3.

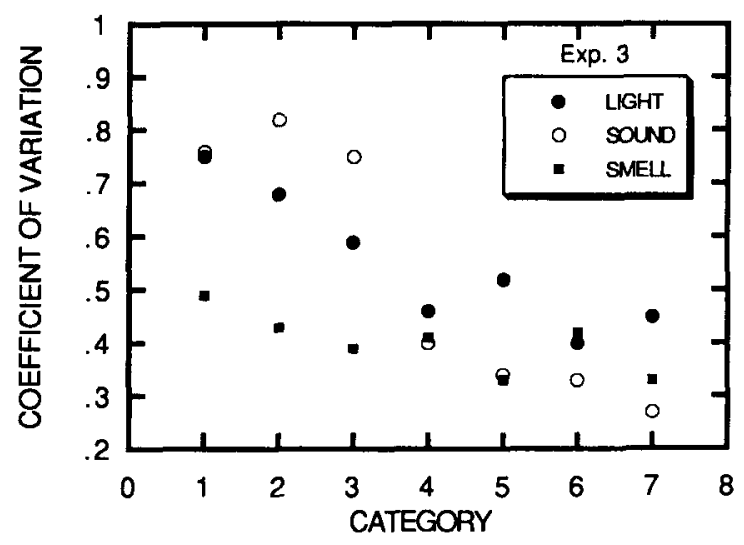

Figure 7. CV (standard deviation/mean) as a function of phrase category for the attributes indicated. Data based on averages across 3 subjects in Experiment 3. 


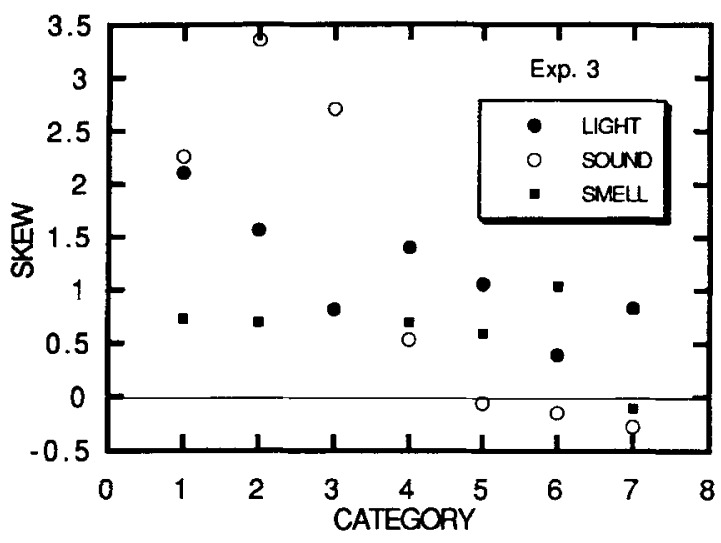

Figure 8. Skew of response distributions as a function of phrase category for the attributes indicated. Data based on averages across 3 subjects in Experiment 3.

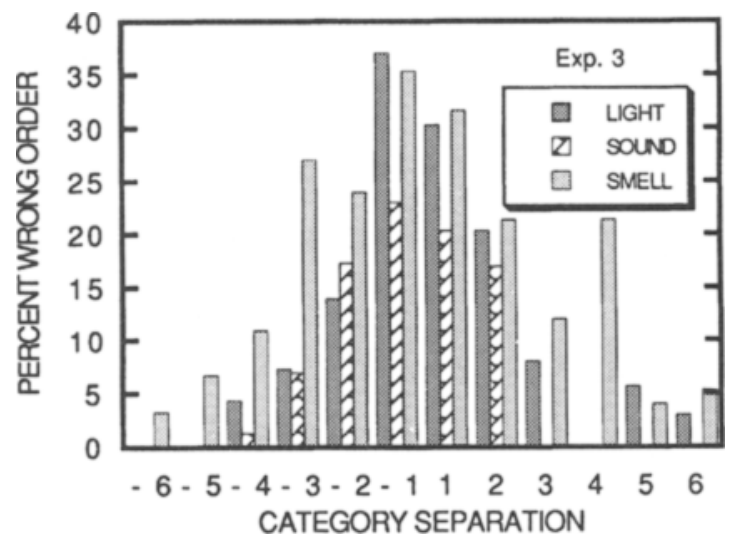

Figure 9. Percent violation of rank order between estimates of successive phrases as a function of separation between their category values. Data presented for three attributes and based on averages across 3 subjects in Experiment 3 .

corresponds to the trend observed when subjects estimate physical stimuli (Figure 3B; Baird, 1997, p. 169).

Sequence effects. Figure 9 shows the percent of trials on which the subjects made an error in the rank ordering of successive images. The averages portray a familiar picture (cf. Figure 4): Most errors are concentrated around the small category separations (between successive trials); few errors are made when category separation is large. This is true for all three attributes. There are also fewer errors (Figure 9) than in Experiment 2 (Figure 4A). This may be due to the fact that, in the present case, the attributes were blocked into different sessions. In Experiment 2, the attributes were mixed within the same session. Sequential effects are generally weaker in mixed-modality designs (Ward, 1990).

Figure 10 shows the correlation between successive responses plotted as a function of category separation on successive trials. The triangle pattern (Figure 5B) found with physical stimuli is not apparent here. The correla- tions fluctuate around zero and show no sign of a systematic dependence on category separation. This is consistent with the findings from Experiment 2 (Figure 5A). We conclude that the lack of a triangle pattern in Experiment 2 did not stem from mixing different modalities in the same session. Nor can the lack of this effect be due to the fact that the subjects in Experiment 2 all had the same response scale. Our failure to find a sequence effect (manifested as the triangle pattern) is the only result for images that differs substantially from results for physical stimuli.

In summary, with the exception of the triangle pattern, the findings for images correspond rather closely to those for physical stimuli. These effects are robust; they occur for subjects tested by two experimental designs. The issue we examined in the next two experiments was the internal consistency of the magnitude estimates of images, as assessed by cross-modality matching.

Marks (1982) has shown that subjects can reliably produce the sensory intensity aroused by two physical attributes (e.g., light and sound) referred to in a verbal metaphor. In his study, subjects set the loudness and brightness of physical stimuli to match the levels represented by the metaphor. In our experiment, we asked subjects to produce (select) a phrase representing imaged intensity in one modality to a phrase representing imaged intensity in another. The primary question was whether subjects would tend to match phrases assigned the same numerical values in Experiments 2 and 3.

\section{EXPERIMENT 4}

The rationale for Experiment 4 was to check the internal consistency of the magnitude estimates given in Experiment 2 . The procedure used was cross-modality matching, in which each of three attributes (light, sound, smell) served as both stimulus and response continua for each of the other two attributes (six pairs of matches).

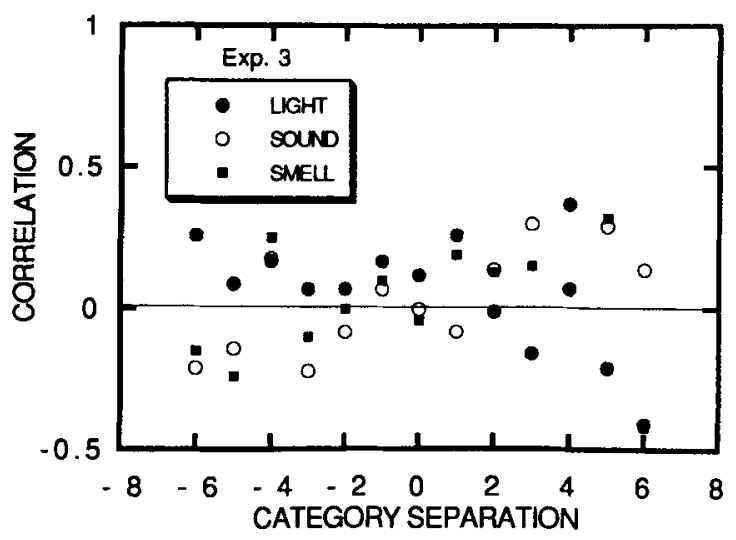

Figure 10. Correlation between successive responses to phrases as a function of separation between their category values. Data presented for three attributes and based on averages across 3 subjects in Experiment 3. 


\section{Method}

Subjects. The subjects were 18 undergraduates ( 13 women and 5 men) enrolled in an introductory psychology course at Dartmouth College. Each received nominal course credit for participation.

Procedure. The general procedure was an extension of a technique introduced by Baird and Vernon (1965) and developed more fully by Heller (1985) and Sebald (1990).

The phrase pool (from Experiment 1) was first pruned to eliminate all duplicates. This was done because it would make no sense for the subjects to attempt to change the intensity of an image (aroused by a phrase) and then be faced with the phrase they started with.

Next, the phrases were rank ordered by the experimenters according to the magnitude of the mean judgments in Experiment 2. Ten stimulus phrases were selected from the pool for each attribute. The numerical intervals between phrases (as assigned by the subjects in Experiment 2) were approximately equal, but we did not include the extreme values. This allowed room for comparison phrases to evoke images of both greater and lesser intensity than the stimulus phrases. The 30 stimulus phrases were presented in a random order (different for each subject) on a Macintosh platform.

Forty-nine comparison phrases (approximately equally spaced) were selected that spanned the full range of numerical values generated in Experiment 2. The phrases were separated into two tiers of options, each containing seven phrases. The response tiers were established by the experimenters. The entire range was first divided into seven categories (roughly equal intervals) containing sets of values (e.g., phrases with responses of 1 to 14,15 to $27 \ldots 81$ to 96). A phrase in the middle of each of the seven categories was selected as a Tier 1 response option.

The options in Tier 2 were subsets of the categories containing the Tier 1 options. This second tier consisted of seven phrases, including the Tier 1 option selected by the subject and six surrounding phrases (three greater than and three less than the Tier 1 option). Therefore, the decision about which particular phrases comprised the Tier 2 options was done "on the fly" by the computer program after the subject chose a phrase from Tier 1 .

Two comparison subsets were chosen for each attribute: one subset was employed when the comparison attribute (e.g., sound) was matched to one of the remaining attributes (e.g., smell); the other subset was used for matching the alternative attribute (in this example, light). There was no duplication of phrases between the two response sets. This was possible because different phrases generated the same mean estimate in Experiment 2.

Each of the response options (phrases) appeared on the screen with a number next to it (on the left) so the subject could distinguish among them. The positions of the numbers ( 1 to 7 ) and the phrases were randomized on each trial and within each response tier. The subjects selected a match by typing the number corresponding to their choice of response (comparison) phrase.

The instructions read in part:

In this experiment you match the intensity aroused by a scenario associated with one stimulus attribute (light, sound, or smell) with the image aroused by a scenario referring to another attribute (light, sound. or smell). You will first be presented with a sentence at the top of the screen. This is the target sentence. For example, a scene evoking the image of a light. Below the target sentence will be seven comparison sentences, each evoking an image of a second scene. For example, scenes referring to sound. Each of these sentences will be accompanied by a number. The task is to select a sentence from the comparison list that evokes an image of intensity that matches the image of intensity evoked by the target sentence. Read over all the comparison sentences until you find one that best matches the intensity of the target scenario. Then type in the associated number.

You will then be presented with the same target sentence and seven additional comparison sentences. One of these sentences will be the same one you chose initially. Please select the comparison sentence that best matches the target sentence. You may choose any of the seven, includ- ing the sentence you selected the first time. The purpose of this second set of sentences is to allow you to fine-tune your selection so that it best matches the target sentence.

\section{Results and Discussion}

The analysis of cross-modality matches of phrases is somewhat different from what is performed when the stimuli are physical attributes. In a perceptual experiment, subjects give magnitude estimates of physical intensities for, say, lights and sounds (in separate experiments). The logarithm of the numbers is then plotted against the logarithm of the intensities to obtain a slope (exponent of S. S. Stevens's power law). That is, for attributes $\mathrm{L}=$ light and $\mathrm{S}=$ sound:

$$
\mathrm{R}_{\mathrm{L}}=\lambda \mathrm{L}^{\gamma_{\mathrm{L}}}
$$

and

$$
\mathrm{R}_{\mathrm{S}}=\lambda \mathrm{S}^{\gamma} \text {. }
$$

Now, if the perceived intensity of the light is adjusted to match the perceived intensity of the sound by a crossmodality method, the left-hand terms in Equations 2 and 3 are equal $\left(R_{L}=R_{S}\right)$. This means that the terms on the right-hand sides are also equal. Therefore,

$$
\mathrm{L}^{\gamma_{\mathrm{L}}}=\mathrm{S}_{\mathrm{S}}^{\gamma_{\mathrm{S}}} \text {. }
$$

Solving for $\mathrm{L}$ in Equation 4,

$$
\mathrm{L}=\mathrm{S}_{\mathrm{s}}^{\gamma_{\mathrm{L}} \gamma_{\mathrm{L}}}
$$

If the logarithm of the light intensity is then plotted against the logarithm of the sound intensity, the slope should equal the ratio of the exponents (Equation 5) obtained in the earlier experiment using magnitude estimation. If this holds true, we conclude that transitivity holds for the exponents and that number biases are not distorting the results (Baird \& Noma, 1978; S. S. Stevens, 1975). For the case of images aroused by phrases, however, we do not have values to substitute into the equations for the physical intensities of $L$ and $S$. Therefore, Equations 4 and 5 cannot even be considered; none of the terms in these equations is known. What is known is that the right-hand sides of Equations 2 and 3 are equal once a match has been made. We also have corresponding numbers for $R_{L}$ and $R_{S}$ from Experiment 2 . Therefore, if everything fits together perfectly, these two numbers should be the same when the two phrases are matched $\left(R_{L}=R_{S}\right)$. One way to look at the data, then, is to plot the numerical values for matched phrases against each other. When this is done, one expects to see a linear function with a slope of 1.0. Failing this, one is satisfied with a linear relation as an indication of internal consistency.

The phrases were characterized by their respective arithmetic means from Experiment 2. The mean response associated with the comparison phrase selected as a Tier 2 option was then plotted against the mean response associated with the stimulus phrase. If the intensities aroused by both images were the same, the cross-modality 

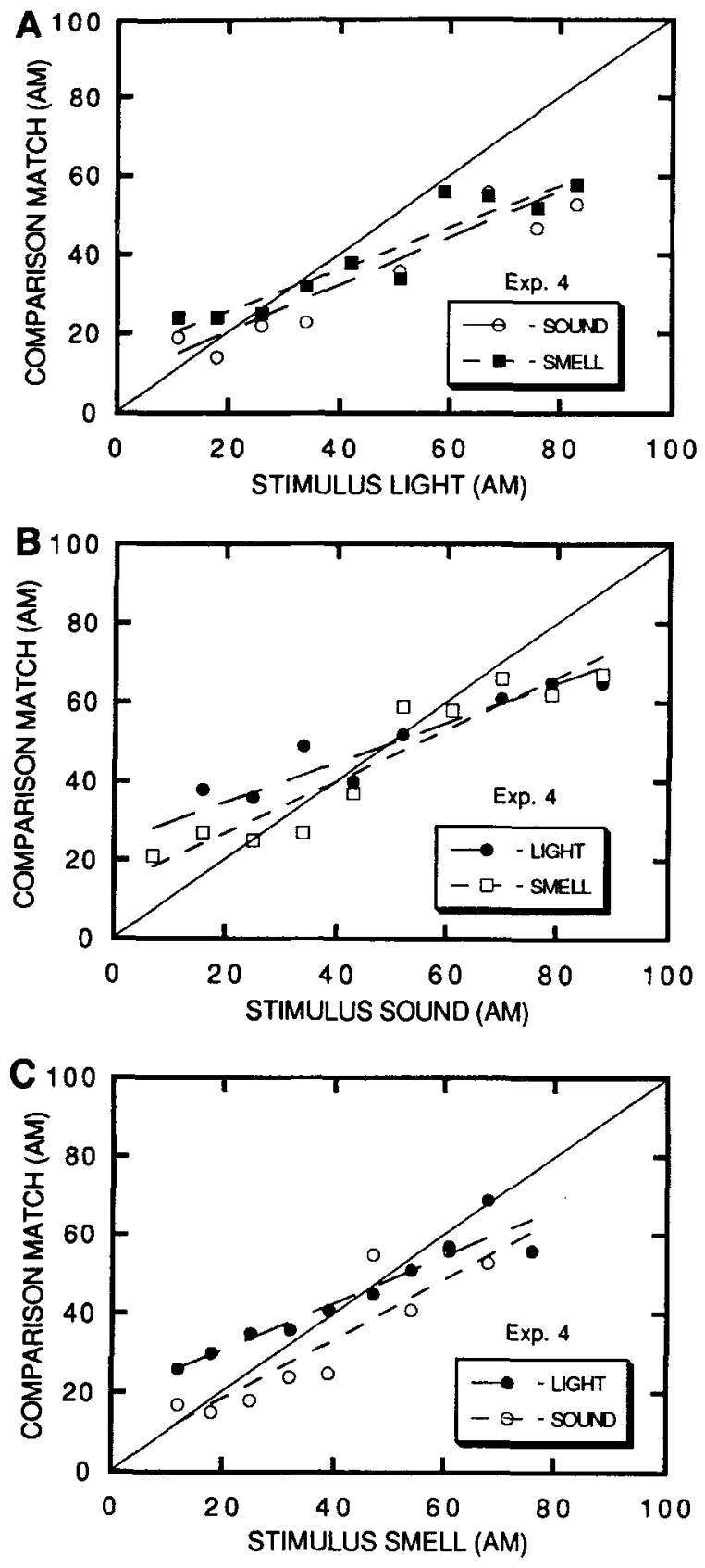

Figure 11. Mean (arithmetic) magnitude estimate of a comparison phrase matched to a standard phrase in a cross-modality matching procedure. Data represent averages across 5 subjects in Experiment 4 when the stimulus phrase aroused an image of light (A), sound (B), and smell (C).

match should yield the same mean response for both the stimulus phrase and the comparison phrase. The data are shown in Figures $11 \mathrm{~A}, 11 \mathrm{~B}$, and $11 \mathrm{C}$ for the stimulus attributes of light, sound, and smell, respectively.

The straight lines through the data sets represent the best-fitting linear functions (correlations from $r=.91$ to $r=.95$ ). The response consistency indicated by the cross-modality matches can be considered only moderate. A perfect match for all stimulus-comparison pairs would be indicated if the data points fell on the diagonal line through the origin. This does not occur. Instead, there is a compression of the range of numbers associated with a match. In general, the matches to weak stimulus images tend to be above the diagonal line, and matches to strong images tend to fall below the line. It is difficult to interpret these results in a definitive manner because cross-modality matching of physical stimuli often leads to serious intransitivities (e.g., Baird et al., 1980; Mashhour \& Hosman, 1968), more dramatic than what is suggested by the data in Figure 11 .

A "regression effect" is often found in cross-modality matching with physical stimuli (J. C. Stevens \& Marks, 1965 ; S. S. Stevens, 1975, p. 102). The comparison attribute under the subject's control is compressed in its range of intensity relative to that of the stimulus attribute. Responses to images are apparently subject to the same regression effect, at least when judgments are obtained in a mixed-modality design. In the final experiment in this series, we reexamined the question of response consistency and the robustness of the regression effect under conditions in which the stimulus and response phrases were blocked in sessions according to the attribute pair being tested.

\section{EXPERIMENT 5}

The purpose of Experiment 5 was to test the generality of the findings of Experiment 4 by using a different method for eliciting responses. Cross-modality matches were obtained in blocks of trials with the same stimulus and response attributes.

\section{Method}

Subjects. The subjects were the same 3 graduate students ( 2 women and 1 man) who participated in Experiment 3. Each subject received $\$ 50$ compensation.

Procedure. The phrases were rank ordered separately for each subject according to the magnitude of the numerical estimate he/she gave in Experiment 3. Ten stimulus phrases were selected from the pool for each attribute such that they spanned the entire range of estimates. Two comparison response sets were selected for each attribute: one used when one of the other (two possible) attributes was the stimulus, and the other used when the remaining attribute was the stimulus.

The comparison sets spanned the range from the lowest to the highest values assigned by the subject in Experiment 3 . Because each subject used a different number of response options in Experiment 3 (see Table 2), the number of options in Experiment 5 differed among the 3 subjects (Subject 1, 25 alternative phrases; Subject 2, 17 alternatives; Subject 3, 11 alternatives).

On each trial, the target phrase appeared at the top of the screen. A comparison phrase was randomly selected from the response pool and presented below the stimulus phrase. By pressing the ">" or "<" symbol on the keyboard, the subject changed the comparison phrase (scenario) to evoke a more or less intense image. The comparisons were ordered from low to high in terms of the intensity of the image they previously evoked for the same subject in Experiment 3 . The subjects were told that the phrases were rank or- 

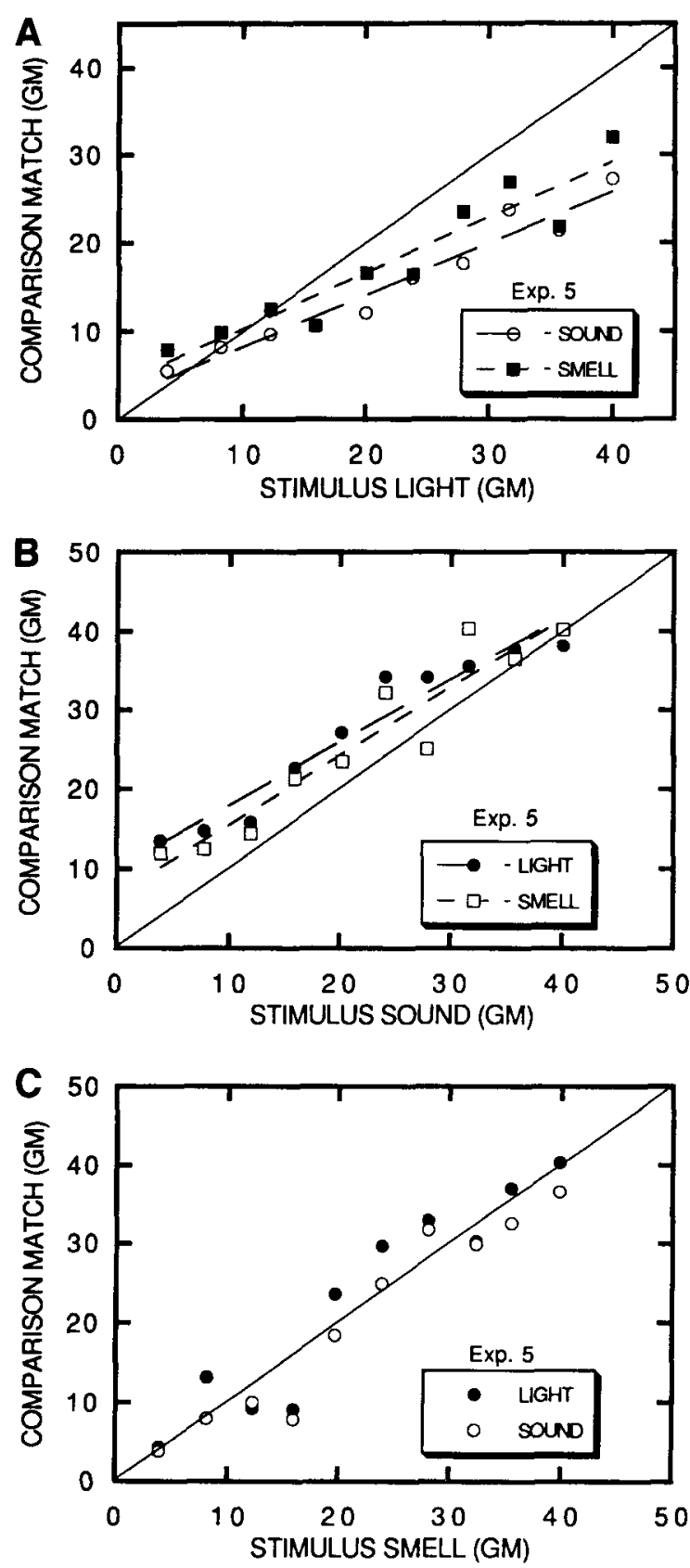

Figure 12. Mean (geometric) magnitude estimate of a comparison phrase matched to a standard phrase in a cross-modality matching procedure. Data represent averages across 3 subjects in Experiment 5 when the stimulus phrase aroused an image of light (A), sound (B), and smell (C).

dered in this way. The subject continued changing the comparison scenarios until she or he found one that matched the intensity of the target scenario. Pressing the "return" key cleared the screen and triggered the next stimulus phrase. This procedure was more akin to the one employed in cross-modality matching of physical stimuli than was the procedure used in Experiment 4.

The instructions read in part:

In this experiment you are asked to match the intensity aroused by a scenario associated with one stimulus attribute (c.g., sound) with the image aroused by a scenario referring to another attribute (e.g., light). You will be presented with two phrases. The top phrase is the target scenario (sound). The bottom phrase is the comparison scenario (light). By adjusting the $<$ and $>$ keys you should change the comparison scenario until you find one that matches the target scenario.

Six matches were made between a stimulus attribute (S) and a comparison attribute $(C)$. The six types of matches were obtained in separate sessions run on different days. The session order was the same for all 3 subjects: (S-light: C-sound), (S-light: $\mathrm{C}$-smell), (S-sound: C-light), (S-sound: C-smell), (S-smell: C-light), and (Ssmell: C-sound).

\section{Results and Discussion}

The results are shown in Figure 12, which has the same format as Figure 11. The stimulus and comparison phrases for different attributes were coded as the geometric mean calculated for the same subjects in Experiment 3 . Figures $12 \mathrm{~A}, 12 \mathrm{~B}$, and $12 \mathrm{C}$ represent the stimulus attributes light, sound, and smell, respectively.

Perfect agreement between stimulus and comparison phrases is indicated when data fall on the diagonal line through the origin. This occurs only for the condition in which light $(r=1)$ and sound $(r=.98)$ are matched against smell (Figure 12C). However, when light ( $r=$ $.97)$ and smell $(r=.95)$ are matched against sound (Figure 12B), the points lie roughly parallel to the diagonal, implying that cross-modality matches are consistent with magnitude estimates, except that the matches tend to be a constant amount higher than the stimulus (phrase) values. On the other hand, the data with light as a stimulus ( $r=.98$ matched to sound; $r=.94$ matched to smell) show the same regression effect observed in Experiment 4, as well as in numerous studies of cross-modality matching between physical stimuli (Baird, 1997, p. 110; S. S. Stevens, 1975, p. 102).

In sum, results from a blocking procedure (Experiment 5) correspond fairly well to results with a mixedattribute design (Experiment 4). Taken together, the results offer some support for the notion that cross-modal matches of images aroused by phrases can be predicted by knowledge of the magnitude estimates of the same images judged in isolation.

\section{GENERAL DISCUSSION}

In many ways, the psychophysics of images mirrors the psychophysics of physical stimuli. The major exception is the lack of substantial correlations among responses to successive images generated by phrases. High positive correlations are found with magnitude estimation when successive physical stimuli are close in intensity (Baird et al., 1980; Green et al., 1977; Luce et al., 1980). The failure to find such a correlation pattern for imagery could be because phrases arouse complex images containing multiple stimulus dimensions. The image of an "open box of chocolates lying on a counter top in the kitchen" may evoke an olfactory image of strong sweetness but also a visual image of shapes and colors. Except for the sweetness dimension, there may be little 
equivalence between this composite image and one aroused subsequently to the phrase "the rose garden in my aunt's backyard."

The findings also suggest that at least some sequence effects with physical stimuli have a sensory basis. If sequence effects are due only to response bias, one would expect them to have occurred in the present experiments. They did not.

\section{THEORETICAL CONSIDERATIONS}

Assuming that imagery tasks are near relatives of psychophysical tasks, models designed to handle the latter should apply equally well to the former. One recent theory of the processes underlying magnitude estimation distinguishes between sensory-neural and decision-making variables (Baird, 1997). The theory claims that the key to understanding psychophysics rests with the ability to understand the source of response variability, but that two alternative, "mutually completing," theoretical approaches to this problem are equally valid and complementary.

The sensory aggregate model states that response variability occurs because an entire population of neurons is excited by a stimulus, and, on each trial, a brain process samples from this pool. The judgment option model states that response variability occurs because the subject is uncertain about which of many response options should be selected, and, hence, different options are chosen on different trials for the same stimulus. By the proper selection of parameter values, computer simulations based on each model produce data that closely resemble what is observed experimentally, including power functions between stimulus and response magnitudes, CV and skewness functions, and rank-order violations (Baird, 1997).

Space does not permit a detailed description of these two approaches, but their essential elements can be sketched out to suggest possible extensions to the case of imagery. We feel that more empirical evidence is necessary before a quantitative modeling effort is undertaken.

\section{Sensory Interpretation}

When a sense organ is excited by a physical stimulus, an ensemble of neurons fires; each neuron's rate depends on its threshold relative to stimulus intensity. A partial representation of this ensemble is stored in long-term memory (Baird, 1997, chaps. 2 and 7). If the environmental event is multidimensional, then the stored representation is also multidimensional. Assume next that the phrases in the present experiments reactivate stored memories originally laid down by physical events perceived in the past. Magnitude estimates based on the memories (images) should then be described by the same empirical laws appropriate for physical stimuli, depending on the degree to which the stored representation matches the original percept (Baird \& Hubbard, 1992).

In cross-modality matching the mean firing rates from one stimulus attribute (say, sound) is matched to the mean firing rates from another (say, light), and the relative success of this procedure is reflected in the function relating the intensities from the two modalities. The same could be true of images. Marks (1995) reports that people associate attributes in the manner suggested here; for instance, bright lights are spontaneously associated with loud sounds. In the present experimental situation, the memorial representation of intensity associated with a stimulus scene involving one attribute may be matched to the memorial representation of intensity for a scene involving another. By this account, images are subject to the same regression effects found for actual stimuli, because such effects are due to response biases operating in both perception and imagery tasks.

This explanation has much in common with the knowledge-weighting model proposed by Intons-Peterson and her colleagues (Intons-Peterson \& McDaniel, 1991; Intons-Peterson \& Roskos-Ewoldsen, 1989), though they assume that the information retrieved from memory is in a canonical form. Relying on previous work (Hubbard et al., 1989), we favor an explanation that has subjects retrieving memories of specific episodes from the past, more along the lines envisioned by Tulving (1983).

Such an interpretation is also consistent with other findings from our laboratory (Hubbard \& Baird, 1988, 1993) showing that a first-sight (initial) image contains metric information derived from a person's familiarity with scenes actually observed in the past. In experiments by Hubbard et al. (1989), subjects gave distance estimates to recalled and imaged objects and then described the visual context in which the object was imagined. An independent group then sorted these contexts (based on images and memories) according to similarity. No unique characteristics identified the items placed in the two sorted categories. In other words, subjects did not distinguish between those contexts generated in the imagery and memory conditions.

\section{Judgment Interpretation}

When estimating physical stimuli, subjects perceive rank-order relations among stimuli of different intensity. Judgment options are normally distributed (equal variance) around each rank, and these options are mapped onto response values according to number preferences and judgment strategies associated with particular scaling methods, such as category and magnitude estimation (Baird, 1997, chaps. 8-10).

Assume that subjects can rank order the intensities aroused by a set of images, which are identical with or derived from memorial representations of direct percepts. The response preferences and judgment strategies exhibited in estimating images would be identical to those employed in estimating physical stimuli, thus distorting the rank orders in predictable ways. Hence, the empirical relations for images are the same as for physical stimuli. According to this account, cross-modality matching requires the specification of a comparison scene whose rank order within the set of images in one modality matches 
the rank order of the stimulus image within the set in another modality (cf. Krantz, 1972).

The complementary interplay between sensory and judgment factors implies that there are two, equally valid, interpretations of the demonstrated similarity between images and percepts. The strong implication is that it may be difficult to distinguish between the two alternatives based on experimental tests. Besides the wellknown examples from physics (regarding conceptions of light), the notion of complementarity also is mentioned by Estes (1994, p. 257) as a rationale for tolerating the puzzles raised by categorization results in other domains of cognitive psychology. In either case, we argue that the statistical results and functional relations in the present study of imagery are similar to those found in psychophysical studies, because the underlying sensory and/or judgment processes are the same, or nearly so.

Finally, we consider the question of whether or not the phrases in our experiments actually aroused "sensory images." This question is problematic for everyone working in this field. Imagery researchers (e.g., Farah, 1995; Finke, 1985) have spent several decades trying to resolve this issue, and even magnetic resonance techniques have not removed all doubt (Kosslyn et al., 1995). Our experiments do not directly bear on this debate, but all the subjects in our experiments told us that they conjured up perceptual images based on the phrases. Whatever the nature of the actual stimulus, we claim that if two experimental paradigms produce high agreement on a battery of psychophysical measures, then it is likely that they are precipitated by the same underlying conditions. And if we were indeed not studying perceptual imagery, but rather some aspect of language processing, then we have some truly remarkable results on how subjects interpret phrases.

\section{REFERENCES}

Algom, D. (1992). Memory psychophysics: An examination of its perceptual and cognitive prospects. In D. Algom (Ed.), Psychophysical approaches to cognition (pp. 441-513). New York: North-Holland.

BAIRD. J. C. (1986). Numbers and exponents. In B. Berglund, U. Berglund, \& R. Teghtsoonian (Eds.), Fechner Day 86 (pp. 101-106). Stockholm: International Society for Psychophysics.

BaIRD, J. C. (1997). Sensation and judgment: Complementarity theory of psvchophysics. Mahwah, $\mathrm{NJ}$ : Erlbaum.

Baird, J. C., Berglund, B., \& Olsson, M. J. (1996). Magnitude estimation of perceived odor intensity: Empirical and theoretical properties. Journal of Experimental Psychology: Human Perception \& Performance, 22, 244-255.

Baird, J. C., Green, D. M., \& LuCE, R. D. (1980). Variability and sequential effects in cross modality matching of area and loudness. Journal of Experimental Psychology: Human Perception \& Performance, 6, 277-289.

Baird, J. C., \& Hubbard, T. L. (1992). Psychophysics of visual imagery. In D. Algom (Ed.), Psychophysical approaches to cognition (pp. 389-420). New York: North-Holland.

BaIRD, J. C., \& Noma, E. (1978), Fundamentals of scaling and psychophvsics. New York: Wiley.

BAIRD, J. C., \& VERNON, C. W. (1965). Binary estimation. Psychonomic Science, 3, 469-470.

EsTES, W. K. (1994). Classification and cognition. Oxford: Oxford University Press.

Farah, M. J. (1985). Psychophysical evidence for a shared representa- tional medium for mental images and percepts. Journal of Experimental Psychology: General, 114, 91-103.

FARAH, M. J. (1989). The neural basis of mental imagery. Trends in Neurosciences, 12, 395-399.

FARAH. M. J. (1995). The neural bases of mental imagery. In M. S. Gazzaniga (Ed.), The cognitive neurosciences (pp. 963-975). Cambridge, MA: MIT Press.

FINKE, R. A. (1985). Theories relating mental imagery to perception. Psychological Bulletin, 98, 236-259.

FInKE, R. A. (1989). Principles of mental imagery. Cambridge, MA MIT Press.

FINKE, R. A., \& SHEPARD, R. N. (1986). Visual functions of mental imagery. In K. R. Boff, L. Kaufman, \& J. P. Thomas (Eds.), Handbook of perception and human performance (Vol. 2, pp. 37-l to 37-55) New York: Wiley.

Gibson, R. H., \& Tomko, D. L. (1972). The relation between category and magnitude estimates of tactile intensity. Perception \& Psychophvsics, 12, 135-138.

Gracely, R., McGrath, P., \& Dubner, R. (1978). Ratio scales of sensory-affective pain descriptors. Pain, 5, 5-18.

Green, D. M.. LuCE, R. D., \& DUNCAN, J. E. (1977). Variability and sequential effects in magnitude production and estimation of auditory intensity. Perception \& Psychophysics, 22, 450-456.

HARDER, K., \& BAIRD, J. C. (1995). Psychophysical analysis of imagery. Unpublished manuscript, Dartmouth College.

HeFt, M., \& PARKER, S. (1984). An experimental basis for revising the graphic rating scale for pain. Pain, 19, 153-161.

HeLler, O. (1985). Hörfeldaudiometrie mit dem Verfahren der Kategorienunterteilung $(\mathrm{KU})$ [Hearing assessment by the method of category portioning]. Psychologische Beiträge, 27, 478-493.

HuBBaRD, T. L. (1993). Cross-modality matching in mental psychophysics: Brightness and loudness. Perceptual \& Motor Skills, 76 , 1339-1357.

HubBaRD. T. L. (1994). Memory psychophysics. Psychological Research/ Psychologische Forschung, 56, 237-250.

HubBard, T. L., \& Baird, J. C. (1988). Overflow, first-sight, and vanishing point distances in visual imagery. Journal of Experimental $P_{s y-}$ chology: Learning, Memory, \& Cognition, 14, 641-649.

HubBard, T. L., \& Baird, J. C. (1993). The effects of size, clutter, and complexity on vanishing-point distances in visual imagery. Psychological Research/Psychologische Forschung, 55, 223-236.

HubBard, T. L., Kall, D., \& Baird, J. C. (1989). Imagery, memory, and size-distance invariance. Memory \& Cognition, 17, 87-94.

HubBaRD, T. L.. \& STOEKIG, K. (1992). The representation of pitch in musical images. In D. Reisberg (Ed.), Auditory imagery (pp. 199235). Hillsdale, NJ: Erlbaum.

INTONS-PETERSON, M. J. (1983). Imagery paradigms: How vulnerable are they to experimenters' expectations? Journal of Experimental Psychology: Human Perception \& Performance, 9, 394-412.

INTONS-PETERSON. M. J. (1984). Faces, rabbits, skunks, and ducks: Imaginal comparisons of similar and dissimilar items. Journal of Experimental Psychology: Learning, Memory, \& Cognition, 10, 699-715.

Intons-Peterson, M. J., \& MCDANiEl, M. A. (1991). Symmetries and asymmetries between imagery and perception. In C. Cornoldi \& M. A. McDaniel (Eds.), Imagery and cognition (pp. 47-76). New York: Springer-Verlag.

IntOns-Peterson, M. J., \& Roskos-Ewoldsen, B. B. (1989). Sensoryperceptual qualities of images. Journal of Experimental Psychology: Learning, Memory, \& Cognition, 15, 188-199.

Intons-PETERSON, M. J., \& White, A. R. (1981). Experimenter naiveté and imagined judgments. Journal of Experimental Psychology: Human Perception \& Performance, 7, 833-843.

KosSLYN, S. M. (1987). Seeing and imaging in the cerebral hemispheres: A computational approach. Psychological Review, 94, 148-175.

KossLYN, S. M. (1994). Image and brain. The resolution of the imagery debate. Cambridge, MA; MIT Press.

Kosslyn, S. M., Thompson, W. L., Kıм, I. J., \& Alpert, N. M. (1995). Topographical representations of mental images in primary visual cortex. Nature, $\mathbf{3 7 8}, 496-498$.

KRANTZ, D. H. (1972). A theory of magnitude estimation and crossmodality matching, Journal of Mathematical Psychology, 9, 168-199. 
LiNk, S. W. (1992). The wave theory of difference and similarity. Hillsdale, NJ: Erlbaum.

Luce, R. D., Baird, J. C., Green, D. M., \& Smith, F. (1980). Two classes of models for magnitude estimation. Journal of Mathematical Psychology, 22, 121-148.

MARKS, L. E. (1982). Synesthetic perception and poetic metaphor. Journal of Experimental Psychology: Human Perception \& Performance, 8, 15-23.

MARKS, L. E. (1993). Contextual processing of multidimensional and unidimensional auditory stimuli. Journal of Experimental Psychology: Human Perception \& Performance, 19, 227-249.

MARKS, L. E. (1995). Intermodal similarity and cross-modality matching: Coding perceptual dimensions. In R. D. Luce, M. D'Zmura, D. Hoffman, G. J. Iverson, \& A. K. Romney (Eds.), Geometric representations of perceptual phenomena: Papers in honor of Tarow Indow on his 70th birthday (pp. 207-233). Mahwah, NJ: Erlbaum.

Mashrour, M., \& Hosman, J. (1968). On the new "psychophysical law": A validation study. Perception \& Psychophysics, 3, 367-375.

Mitchell, D. B., \& Richman, C. L. (1980). Confirmed reservations: Mental travel. Journal of Experimental Psychology: Human Perception \& Performance, 6, 58-66.

NoRwICH, K. H. (1993). Information, sensation, and perception. New York: Academic Press.

Poulton, E. C. (1989). Bias in quantifying judgments. Hillsdale, NJ: Erlbaum.

Pylyshyn, Z. W. (1984). Computation and cognition. Cambridge, MA: MIT Press.

RoLAND, P. E., \& Gulyás, B. (1994). Visual imagery and visual representation. Trends in Neurosciences, 17, 281-287.

Rosenthal, R. (1976). Experimenter effects in behavioral research. New York: Halsted.

Serald, A. (1990). Category partitioning in relation to category and ratio scales. In F. Müller (Ed.), Fechner Day 90 (pp. 106-111). Stockholm: International Society for Psychophysics.

Shepard, R. N., \& Cooper, L. A. (1982). Mental images and their transformations. Cambridge, MA: MIT Press.

StevenS, J. C., \& Marks, L. E. (1965). Cross-modality matching of brightness and loudness. Proceedings of the National Academy of Sciences, 54, 407-411.

STEVENS, S. S. (1975). Psychophysics: Introduction to its perceptual, neural and social prospects. New York: Wiley.

Stevens, S. S., \& Galanter, E. H. (1957). Ratio scales and category scales for a dozen perceptual continua. Journal of Experimental Psychology, 54, 377-411.

TuLving, E. (1983). Elements of episodic memory. New York: Oxford University Press.

WARD, L. M. (1990). Mixed-method mixed-modality psychophysical scaling. Perception \& Psychophysics, 48, 571-582.

\section{NOTES}

1. Although the results of this study were used only to generate stimuli for the ensuing experiments, the procedures were those of an experiment. Therefore, throughout the paper, we refer to this as Experiment 1.

2. The geometric mean was used because the subjects selected their own response scales. The range of these scales differed widely among the 3 subjects.

\section{APPENDIX \\ Example Phrases for the Attributes Light, Sound, and Smell}

Light ( 1 = "very very $\operatorname{dim}, " 7$ = "very very bright")

1. dying light bulb

2. traffic light

3. my key chain light

4. sunlight on a normal day

5. a car's high beams

6. a camera flash

7. a strobe light when it flashes on

Sound ( 1 = "very very soft," 7 = "very very loud")

1. leaves rustling in a breeze

2. a whisper

3. a mouse squeaking

4. a person talking

5. a crash, like a trashcan spilling bottles everywhere

6. heavy metal music

7. the sound of a subway train passing by you

Smell ( 1 = "very very faint," 7 = "very very strong")

1. wine on a cork

2. the smell of shampoo in a person's hair

3 . day old perfume

4. the smell of freshly cut grass

5 . smoke caught in wool clothes

6. apple pie in the oven

7. the smell of sewage

(Manuscript received April 28, 1998 revision accepted for publication November $23,1998$. 